\title{
Mannose-binding lectin deficiency attenuates renal changes in a streptozotocin-induced model of type 1 diabetes in mice
}

\author{
J. Østergaard • S. Thiel • M. Gadjeva • T. K. Hansen • \\ R. Rasch • A. Flyvbjerg
}

Received: 26 September 2006 / Accepted: 13 March 2007 / Published online: 1 May 2007

(C) Springer-Verlag 2007

\begin{abstract}
Aims/hypothesis An increasing amount of evidence indicates that mannose-binding lectin (MBL) plays a role in the development of diabetic nephropathy. The main objective of the study was to analyse whether MBL influences the effects of diabetes on the kidneys.

Materials and methods In one group of wild-type mice and in one group of MBL double knockout mice we induced diabetes by the use of streptozotocin as a model of type 1 diabetes. Two groups of non-diabetic mice, wild-type and MBL knockout, were also included. By two-way ANOVA we evaluated if MBL modulated the effects of diabetes by testing the interaction between diabetes and MBL.

Results MBL interacted with the effects of diabetes on three outcome measures: kidney weight $(p<0.001)$, urinary albumin excretion $(p=0.001)$ and the expression of colla-
\end{abstract}

J. Østergaard · T. K. Hansen · A. Flyvbjerg $(\bowtie)$

The Medical Research Laboratories, Clinical Institute

and Medical Department M (Diabetes and Endocrinology),

Aarhus University Hospital,

Nørrebrogade 44,

8000 Aarhus C, Denmark

e-mail: allan.flyvbjerg@dadlnet.dk

S. Thiel $\cdot$ M. Gadjeva

Department of Medical Microbiology and Immunology,

University of Aarhus,

Aarhus, Denmark

R. Rasch

Department of Cell Biology, Institute of Anatomy,

University of Aarhus,

Aarhus, Denmark

R. Rasch

Electron Microscopy Laboratory, Clinical Institute,

Aarhus University Hospital,

Aarhus, Denmark gen IV $\alpha 1$ (Col4al) mRNA ( $p=0.002)$. This means that the effects that diabetes normally has on these parameters were significantly modified by MBL. MBL showed a tendency to interact with the effects of diabetes on glomerular basement membrane thickness and total mesangial volume ( $p=0.065$ and $p=0.063$, respectively). Glomerular volume and total mesangial volume were significantly smaller in animals lacking MBL than in wild-type animals $(p=0.006$ and $p=0.047$, respectively).

Conclusions/interpretation These findings, for the first time, show that the degree of kidney alteration as a consequence of diabetes is modified by MBL. These findings support a pivotal role of MBL in the development of diabetic kidney disease.

Keywords Albumin excretion - Animal · Collagen · Complement - Diabetic angiopathy - Diabetic nephropathy . Kidney weight $\cdot$ Mannose-binding lectin · Type 1 diabetes

$\begin{array}{ll}\text { Abbreviations } \\ \text { BMT } & \text { glomerular basement membrane thickness } \\ \text { BW } & \text { bodyweight } \\ \text { CTGF } & \text { connective tissue growth factor } \\ \text { D-KO } & \text { diabetic MBL knockout } \\ \text { D-WT } & \text { diabetic wild-type } \\ \text { LM } & \text { light microscopy } \\ \text { MAC } & \text { membrane-attack complex } \\ \text { MBL } & \text { mannose-binding lectin } \\ \text { ND-KO } & \text { non-diabetic MBL knockout } \\ \text { ND-WT } & \text { non-diabetic wild-type } \\ \text { RT-PCR } & \text { real-time PCR } \\ \text { STZ } & \text { streptozotocin } \\ \text { UAE } & \text { urinary albumin excretion in 24 h } \\ \text { VEGF-A } & \text { vascular endothelial growth factor A } \\ \text { VEGFR-2 } & \text { vascular endothelial growth factor receptor 2 }\end{array}$




\section{Introduction}

Late complications in diabetes mellitus include cardiovascular disease, neuropathy, retinopathy and nephropathy. Diabetic kidney disease alone affects $15-40 \%$ of all patients with type 1 or 2 diabetes [1,2]. Despite the existing intervention strategies, diabetes is still a major single cause of end-stage renal failure. Accordingly, there is an ongoing need for the development of new additional intervention strategies. Recent reports indicate an involvement of mannose-binding lectin (MBL) from the complement system in the pathogenesis of diabetic kidney disease [3]. Under normal conditions MBL does not bind to the body's own structures, but it does possess potential self-reactive properties. A significant association between serum MBL levels and renal function has been reported in normoalbuminuric, microalbuminuric and macroalbuminuric type 1 diabetic patients [4-6]. Furthermore, in a cohort study of type 1 diabetic patients followed for 18 years from diagnosis, serum MBL was a significant predictor of later renal impairment. In patients with MBL levels above the median, $41 \%$ developed micro- or macroalbuminuria, in contrast to $26 \%$ of patients with levels below the median [7]. To evaluate a potential specific effect of MBL on the pathogenesis of diabetic kidney disease, we induced type 1 diabetes in wild-type and genetically modified MBL double knockout mice and examined the functional and structural renal changes. The data were evaluated for interaction between diabetes and MBL, effect of MBL and effect of diabetes.

\section{Materials and methods}

Animals and protocols We used adult, 11-week-old, female double MBL knockout, i.e. lacking both murine forms of MBL (MBL A and MBL C), C57BL/6J background (own breeding, backcrossed six generations for $>95 \%$ C $57 \mathrm{BL} / 6 \mathrm{~J}$ genetic background) [8], and age-matched, female wildtype mice, C57BL/6J background (Taconic, Ry, Denmark). We used only female mice as they reach the adult bodyweight (BW) plateau faster than male mice. The animals had an initial BW of 17-23 g and were housed six to eight per cage in a room with a $12 \mathrm{~h}$ light-dark cycle (light on $07.00-19.00 \mathrm{~h}$ ), a temperature of $21 \pm 1^{\circ} \mathrm{C}$ and humidity of $55 \pm 5 \%$. Animals had free access to autoclaved standard chow (Altromin \#1324; Lage, Germany) and autoclaved tap water. Diabetes was induced in wild-type and MBL knockout mice by five i.p. injections of streptozotocin (STZ) (Upjohn, Kalamazoo, MI, USA) on five consecutive days (doses of $45 \mathrm{mg} / \mathrm{kg} \mathrm{BW}$ ). The animals were re-injected with doses of $45 \mathrm{mg} \mathrm{STZ} / \mathrm{kg}$ BW i.p. until diabetes was achieved. When mean blood glucose reached $\geq 16 \mathrm{mmol} / \mathrm{l}$ in the two diabetic groups we started the experimental period. Only animals without ketonuria or signs of illness (i.e. fast weight losses) were included. Principles of laboratory animal care (NIH publication no. 85-23, revised 1985) were followed and the study complied with the Danish regulations for care and use of laboratory animals.

The mice were randomised into four groups: (1) nondiabetic wild-type animals (ND-WT, $n=7$ ); (2) non-diabetic MBL knockout animals (ND-KO, $n=8$ ); (3) diabetic wildtype animals (D-WT, $n=11$ ); and (4) diabetic MBL knockout (D-KO, $n=11$ ). BW and blood glucose were measured regularly throughout the study. Food consumption was determined at the beginning and end of the study. Eight weeks after induction of diabetes the mice were placed in metabolism cages to collect $24 \mathrm{~h}$ urine samples for determination of urinary albumin excretion (UAE). The animals were killed under anaesthesia by ketamine (Ketaminol Vet; Intervet, Skovlunde, Denmark) and xylazine (Narcoxyl Vet; Intervet) using a dose of $100 \mathrm{mg} / \mathrm{kg} \mathrm{BW}$ ketamine and $10 \mathrm{mg} / \mathrm{kg}$ BW xylazine i.p. and non-fasting blood samples were drawn by heparinised capillary tubes from the retroorbital venous plexus. Blood samples were stored at $-80^{\circ} \mathrm{C}$ until analysis was performed. The kidneys, livers and hearts were dissected and weighed. The kidney poles were snap frozen in liquid nitrogen for later determination of mRNA expression by real-time PCR (RT-PCR). The middle piece of the left kidney (including the papilla) was fixed in $4 \%$ paraformaldehyde for determination of glomerular volume by light microscopy (LM). The middle piece of the right kidney (including the papilla) was fixed in $0.1 \mathrm{~mol} / 1$ cacodylate buffer with $2.5 \%$ glutaraldehyde and 2\% paraformaldehyde for determination of glomerular basement membrane thickness (BMT) and mesangial fraction by electron microscopy.

Determination of blood glucose and urine analysis Blood glucose was measured weekly in tail-capillary blood by Precision Xtra Plus (Abbott Laboratories, MediSence Products, Bedford, MA, USA). Urine was tested for glucose and ketone bodies by a Combur ${ }^{5}$ Test D (Roche Diagnostics GmbH, Mannheim, Germany).

Determination of UAE and urinary creatinine concentration Urine samples were stored at $-20^{\circ} \mathrm{C}$ until the assay was performed. UAE was determined in $24 \mathrm{~h}$ urine collections by a commercially available kit, the Mouse Albumin ELISA Quantification Kit (Bethyl Labatories, Inc., Montgomery, TX, USA) according to the manufacturer's instructions. Urinary creatinine concentration was measured by an automated technique adapted from the method of Jaffé and corrected for the prevailing glucose content due to interference in the Jaffé reaction $[9,10]$. The intra- and 
inter-assay CVs were $<5$ and $<10 \%$, respectively, for both assays.

Estimation of glomerular volume The paraformaldehydefixed middle part of the left kidney (containing the papilla) was embedded in paraffin for LM examination. Twomicron thick sections were cut on a rotation microtome and stained with haematoxylin and eosin. The mean glomerular tuft volume $\left(V_{\mathrm{G}}\right)$ was determined from measurements of the mean glomerular cross-sectional area $\left(A_{\mathrm{G}}\right)$ at a magnification of $\times 345$ as previously described [11]. Crosssectional area were determined with a two-dimensional version of the nucleator (CAST, Olympus, Denmark) by LM as the average area of a total of 40-80 glomerular profiles (tuft omitting the proximal tubular tissue within the Bowmann capsule). $V_{\mathrm{G}}$ was calculated as: $V_{\mathrm{G}}=\beta / k \times\left(A_{\mathrm{G}}\right)^{1.5}$, where $\beta=1.38$, which is the shape coefficient for spheres (the idealised shape of glomeruli), and $k=1.1$, which is a size distribution coefficient.

Estimation of BMT, mesangial fraction and total mesangial volume The middle part of the right kidney (containing the papilla) was embedded in Epon 825 for electron microscopy examination. Thin sections were cut on a Reichert Ultracut (Leica, Austria) and stained with uranyl acetate and lead citrate. From an electron microscope (CM10, Phillips, Holland), images covering the whole glomerular profile were recorded with a MegaView video camera (Soft Imaging System, Münster, Germany) applying a multiple image alignment system onto a monitor. On the individual images the fraction of mesangium was measured applying a point count technique with a final magnification of $\times 9,200$. BMT was measured in randomised fields at a final magnification of $\times 62,000$ from the same sections described above. BMT was measured applying the orthogonal intercept method as previously described [12]. About 60 measurements were performed per glomerulus and BMT is given as a harmonic mean.

Quantitative RT-PCR After homogenisation of kidney pole tissue by the use of an MM301 Mixer Mill (Retsch, Haan, Germany), total cellular RNA was extracted from renal cortical tissue using a 6100 Nucleic Acid PrepStation (Applied Biosystems, Foster City, CA, USA). The quality of rRNA was estimated by agarose gel electrophoresis by the appearance of two distinct bands visible by fluorescence of ethidium bromide representing intact rRNA. The amounts of RNA extracted were quantified by measuring the absorbance at $260 \mathrm{~nm}$ by spectrophotometry. Reverse transcription from RNA to DNA was performed with a Multiscribe Reverse Transcriptase kit from Applied Biosystems under the following conditions: $25^{\circ} \mathrm{C}$ for $10 \mathrm{~min}$, $48^{\circ} \mathrm{C}$ for $30 \mathrm{~min}$ and $94^{\circ} \mathrm{C}$ for $29 \mathrm{~s}$. The PCR was performed in triplicates of each sample in a volume of $25 \mu \mathrm{l}$ in each well containing RNA, TaqMan Universal PCR MasterMix and primers amplifying TGF- $\beta$ (Tgfb, also known as $T g f b 1)$ (Mm 00441724), connective tissue growth factor (Ctgf) (Mm 00515790), Col4al (185088267A), fibronectin $(F n 1)(1546736)$, vascular endothelial growth factor A (Vegf-A, also known as Vegfa) (Mm 00437304), vascular endothelial growth factor receptor 2 (Vegfr-2, also known as $K d r)$ (Mm 00440099), nephrin (Nphs1) (Mm 497828) and the housekeeping gene, 18S (4319413) purchased from Applied Biosystems. Liver RNA was used as negative controls. Each RT-PCR reaction ran at $50^{\circ} \mathrm{C}$ for $2 \mathrm{~min}$, at $95^{\circ} \mathrm{C}$ for $10 \mathrm{~min}$ and in 40 cycles changing between $95^{\circ} \mathrm{C}$ for $15 \mathrm{~s}$ and $60^{\circ}$ for $1.30 \mathrm{~min}$.

PCR data analysis Data were analysed with the ABI Prism 7000 Sequence Detector Software from Applied Biosystems. The output of amplification was measured in the exponential phase of the reaction as the threshold cycle/Ctvalue, which is defined as the cycle number at which amplification products are detected, corresponding to the point where fluorescent intensity exceeds the background fluorescent intensity, which is $10 \times \mathrm{SD}$ of the baseline. The average of triplicates from each sample was used. The relative quantification of target gene was calculated by the formula $(1 / 2)^{\text {Ct-target }}$ gene-Ct-housekeeping gene, which is described in the Users Bulletin 2, 1997, from Perkin-Elmer (Perkin-Elmer Cetus, Norwalk, CT, USA) [13].

Statistical analysis The study was a $2 \times 2$ factorial experiment. The four groups of animals were generated from two factors: one factor was diabetes (yes/no) and the other factor was MBL status (wild-type/MBL knockout). By two-way ANOVA models the questions of interest were evaluated. The main question of interest was addressed first: the interaction of diabetes and $\mathrm{MBL}$ status $(\mathrm{D} \times \mathrm{MBL})$, i.e. is the effect of diabetes on the various outcome measures different in the presence of MBL (i.e. in the wild-type animals) than in the absence of MBL (i.e. in the MBL knockout animals)? When variables showed interaction between diabetes and MBL $(\mathrm{D} \times \mathrm{MBL})$ we tested the hypothesis: No difference between the two non-diabetic groups, i.e. no effect of MBL in non-diabetic mice. When variables showed no interaction between diabetes and MBL (D $\times$ MBL) the effects of MBL (wild-type vs MBL knockout) are independent of diabetes (no diabetes vs diabetes) and the effects of diabetes (no diabetes vs diabetes) are independent of MBL (wild-type vs MBL knockout). Thus we tested the hypothesis: No overall effect of MBL status. If no effect of MBL we tested the hypothesis: No effect of diabetes. If MBL did influence the outcome no further tests were performed.

The ANOVA models were fitted after consideration of appropriated transformations of the data to achieve near- 
normality and equal variances. After these considerations one-way tests were performed to test if the groups differed overall or not. We only tested the hypotheses mentioned above if the mean of the variable differed significantly between the four groups. For data that could not be transformed to achieve near-normality the Mann-Whitney rank sum test was used. All data from the RT-PCR measurements were transformed by the natural logarithm to give comparisons as ratios rather than differences. Liver weight could not be transformed to achieve near-normality. Measurements by electron microscopy and RT-PCR were made on selected animals of each group (see Table 1). This reduction in numbers was made due to technical limitations. All selections were random.

All data are expressed as means \pm SEM, with $n$ indicating the number of mice studied (number as stated in the Animals and protocols section except when other numbers are given) or mean and $95 \%$ CIs. $p$ values $<0.05$ are considered as significant. $p$ values $<0.10$ and $>0.05$ are considered tendency. Statistical analysis was performed using the statistical package STATA for Microsoft Windows.

\section{Results}

$B W$, blood glucose and food consumption At the start and end of the study the mean BW did not differ significantly between the four groups (data not shown). Food consumption, which was measured at group basis, did not differ between the four groups at the start of the study. By the end of the study diabetic animals had increased food consumption when compared with non-diabetic animals. No difference in food consumption was observed, either between the non-diabetic groups or between the diabetic groups (data not shown). The average levels of blood glucose in the diabetic groups during the study period were $16.1 \pm$ $0.4 \mathrm{mmol} / \mathrm{l}(\mathrm{D}-\mathrm{WT})$ and $16.1 \pm 0.5 \mathrm{mmol} / \mathrm{l}$ (D-KO). The average blood glucose levels in the non-diabetic groups were $7.2 \pm 0.3 \mathrm{mmol} / \mathrm{l}(\mathrm{ND}-\mathrm{WT})$ and $6.6 \pm 0.3 \mathrm{mmol} / \mathrm{l}$ (NDKO). The blood glucose level did not differ between the two diabetic groups or the two non-diabetic groups.

Kidney weight, glomerular volume and UAE The effect of diabetes on kidney weight (Table 1 and Fig. 1) was

Table 1 Summarised data and statistical information by group

\begin{tabular}{|c|c|c|c|c|c|c|c|}
\hline & \multirow[t]{2}{*}{ ND-WT } & \multirow[t]{2}{*}{ ND-KO } & \multirow[t]{2}{*}{ D-WT } & \multirow[t]{2}{*}{$\mathrm{D}-\mathrm{KO}$} & \multicolumn{3}{|l|}{$p$ values $^{\mathrm{a}}$} \\
\hline & & & & & $\mathrm{D} \times \mathrm{MBL}$ & MBL & DM \\
\hline Kidney weight (mg) & $\begin{array}{c}118.0(111.4- \\
124.6)(7)\end{array}$ & $\begin{array}{l}122.8(109.7- \\
135.8)(8)\end{array}$ & $\begin{array}{c}164.5(155.2- \\
173.7)(11)\end{array}$ & $\begin{array}{l}123.6(110.0- \\
137.2)(11)\end{array}$ & $<0.001$ & & \\
\hline $\begin{array}{l}\text { Glomerular volume } \\
\left(\times 10,000 \mathrm{~m}^{3}\right)\end{array}$ & $\begin{array}{l}19.8(17.5- \\
22.1)(7)\end{array}$ & $\begin{array}{l}18.1(16.5- \\
19.7)(8)\end{array}$ & $\begin{array}{r}23.6(22.0- \\
25.2)(11)\end{array}$ & $\begin{array}{l}20.6(18.5-22.7) \\
\quad(11)\end{array}$ & 0.461 & 0.006 & \\
\hline $\mathrm{UAE}(\mathrm{mg} / 24 \mathrm{~h})$ & $\begin{array}{l}66.7(44.7- \\
99.4)(7)\end{array}$ & $\begin{array}{l}181.3(128.4- \\
255.8)(8)\end{array}$ & $\begin{array}{c}601.8(446.9- \\
869.6)(11)\end{array}$ & $\begin{array}{l}509.0(364.5- \\
710.8)(11)\end{array}$ & 0.001 & & \\
\hline BMT (nm) & $\begin{array}{l}194.2(182.2- \\
206.2)(5)\end{array}$ & $\begin{array}{l}196.8(176.8- \\
216.9)(6)\end{array}$ & $\begin{array}{l}227.3(200.0- \\
254.7)(6)\end{array}$ & $\begin{array}{l}198.2(180.9- \\
215.5)(5)\end{array}$ & 0.065 & 0.142 & 0.051 \\
\hline $\begin{array}{l}\text { Mesangial volume, total } \\
\left(\times 10,000 \mathrm{\mu m}^{3}\right)\end{array}$ & $\begin{array}{l}4.1(2.9-5.4) \\
(5)\end{array}$ & $\begin{array}{l}4.0(3.1-5.0) \\
(6)\end{array}$ & $\begin{array}{l}6.6(5.7-7.5) \\
(6)\end{array}$ & $5.0(3.9-6.0)(5)$ & 0.063 & 0.047 & \\
\hline $\begin{array}{l}\text { Mesangial volume, fraction ( } \% \text { of } \\
\text { glomerular volume) }\end{array}$ & $\begin{array}{l}21.4(14.0- \\
28.8)(5)\end{array}$ & $\begin{array}{l}21.8(17.9- \\
25.7)(6)\end{array}$ & $\begin{array}{l}29.9(26.0- \\
33.7)(6)\end{array}$ & $\begin{array}{l}25.8(23.2-28.4) \\
\quad(5)\end{array}$ & 0.220 & 0.311 & 0.002 \\
\hline $\operatorname{Tg} f b$ (arbitrary units $\left.\times 10^{-5}\right)$ & $\begin{array}{c}6.06(4.96- \\
7.39)(7)\end{array}$ & $\begin{array}{c}5.52(4.56- \\
6.67)(7)\end{array}$ & $\begin{array}{c}13.92(10.87- \\
17.83)(7)\end{array}$ & $\begin{array}{l}10.12 \\
\quad(5.56: 18.40)(6)\end{array}$ & 0.392 & 0.130 & $<0.001$ \\
\hline Ctg $f$ (arbitrary units $\times 10^{-4}$ ) & $\begin{array}{c}3.50(3.00- \\
4.08)(7)\end{array}$ & $\begin{array}{c}3.74(2.87- \\
4.87)(7)\end{array}$ & $\begin{array}{l}5.30(4.11- \\
6.84)(7)\end{array}$ & $\begin{array}{l}4.20(3.31-5.32) \\
\quad(6)\end{array}$ & 0.125 & 0.431 & 0.008 \\
\hline Col4al (arbitrary units $\times 10^{-4}$ ) & $\begin{array}{c}1.58(1.43- \\
1.74)(7)\end{array}$ & $\begin{array}{l}2.04(1.73- \\
2.39)(7)\end{array}$ & $\begin{array}{c}4.77(4.13- \\
5.51)(6)\end{array}$ & $\begin{array}{l}3.81(2.94: 4.94) \\
(6)\end{array}$ & 0.002 & & \\
\hline Fn1 (arbitrary units $\times 10^{-4}$ ) & $\begin{array}{l}2.93(2.46- \\
3.50)(7)\end{array}$ & $\begin{array}{l}2.72(1.96- \\
3.78)(7)\end{array}$ & $\begin{array}{c}12.83(9.93- \\
16.58)(7)\end{array}$ & $\begin{array}{l}8.75(5.46-14.02) \\
\quad(6)\end{array}$ & 0.232 & 0.092 & $<0.001$ \\
\hline Vegf-A (arbitrary units $\times 10^{-4}$ ) & $\begin{array}{c}7.00(6.42- \\
7.63)(7)\end{array}$ & $\begin{array}{c}7.73(6.67- \\
8.97)(7)\end{array}$ & $\begin{array}{c}5.55(4.78- \\
6.45)(7)\end{array}$ & $\begin{array}{l}5.76(5.39-6.16) \\
\quad(6)\end{array}$ & 0.542 & 0.169 & $<0.001$ \\
\hline Heart weight (mg) & $\begin{array}{c}100.0(96.9- \\
103.1)(7)\end{array}$ & $\begin{array}{c}101.1(95.1- \\
107.1)(8)\end{array}$ & $\begin{array}{r}93.3(86.9- \\
99.6)(11)\end{array}$ & $\begin{array}{l}91.1(87.7-94.5) \\
(11)\end{array}$ & 0.481 & 0.711 & 0.001 \\
\hline
\end{tabular}

Values listed for UAE, Tgfb, Ctgf, Col4al, Fnl and Vegf-A were obtained by back-transformation of logged data

${ }^{a} \mathrm{D} \times \mathrm{MBL}, p$ values for the 'no interaction between diabetes and MBL'; MBL, $p$ values of the hypothesis 'no effect of MBL'; DM, $p$ values of the hypothesis 'no effect of diabetes.'

Empty cells indicate that the test was not applied. See "Materials and methods" section for further details. 


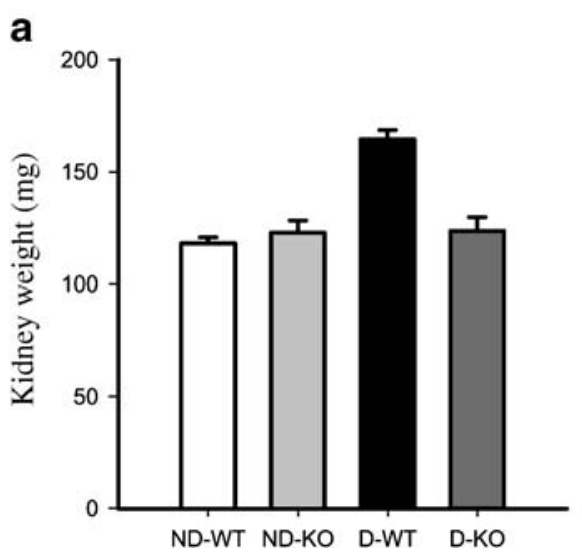

Fig. 1 Right kidney weight (a), glomerular volume (b) and UAE (c) in ND-WT $(n=7)$, ND-KO $(n=8)$, D-WT $(n=11)$ and D-KO $(n=11)$ animals. Error bars indicate SEM by group. Data on UAE needed transformation to achieve near-normality and thus the geometric

b

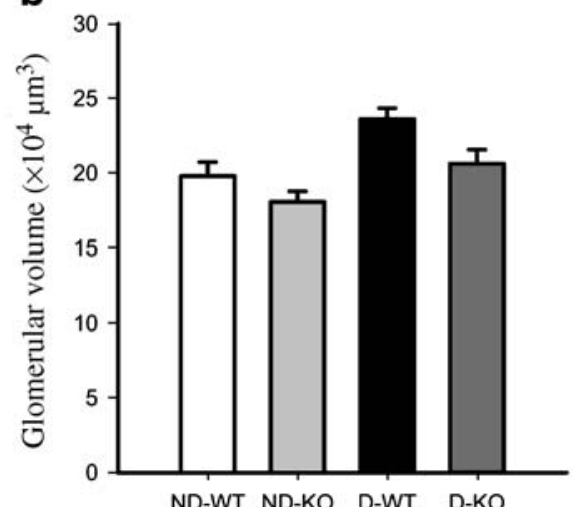

C

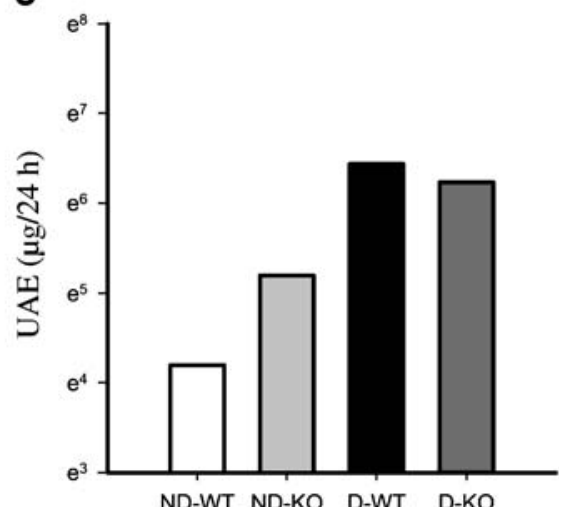
means are illustrated (see Table 1 for back-transformed geometric means and back-transformed 95\% CIs). See "Materials and methods" section and Table 1 for further details

significantly modified by MBL, i.e. we observed interaction of diabetes and MBL $(\mathrm{D} \times \mathrm{MBL})$ on kidney weight $(p<0.001)$. Second, we tested the two non-diabetic groups against each other, but found no difference in mean $(p=0.59)$.

On glomerular volume we found no interaction $(\mathrm{D} \times \mathrm{MBL})$ (Table 1 and Fig. 1). Thus, we tested if MBL (wild-type vs knockout) had any effect on this measure. MBL did significantly decrease the glomerular volume by $24,772 \mu \mathrm{m}^{3}(95 \%$ CI $7,730-41,813)(p=0.006)$.

UAE (Table 1 and Fig. 1) showed an interaction between diabetes and MBL $(p=0.001)$. Second, we found a significant difference between the non-diabetic groups, as UAE in the non-diabetic MBL knockout animals was increased 2.72-fold (95\% CI 1.66-4.45) compared with the non-diabetic wild-type animals $(p<0.001)$.

$B M T$, total mesangial volume and mesangial fraction BMT (Table 1 and Fig. 2) showed a tendency to interaction between diabetes and MBL, although this did not reach significance $(p=0.065)$. MBL did not influence BMT ( $p=$ 0.142 ) and the effect of diabetes alone did not reach statistical significance $(p=0.051)$, but only tended to.

A tendency to interaction $(\mathrm{D} \times \mathrm{MBL})$ was found on the total mesangial volume $(p=0.063)$, but this did not reach statistical significance (Table 1 and Fig. 2). MBL did significantly influence this measure as the MBL knockout animals had an $8,788 \mu^{3}$ (95\% CI 120-17,456) smaller mesangium than wild-type animals $(p=0.047)$.

The mesangial fraction was not subject to $\mathrm{D} \times \mathrm{MBL}$ interaction $(p=0.220)$ or effects of MBL $(p=0.311)$. Diabetic animals had a $6.4 \%(95 \%$ CI $2.7-10.0)$ larger mesangial fraction than non-diabetic animals $(p=0.002)$.

Renal gene transcription Diabetes and MBL did not show interaction on the outcomes $T g f b$ and $\operatorname{Ctg} f$ (Table 1 and Fig. 3). Likewise we found no significant effect of MBL. The expressions of both $T g f b$ and Ctgf mRNA were increased in the diabetic animals compared with the non-
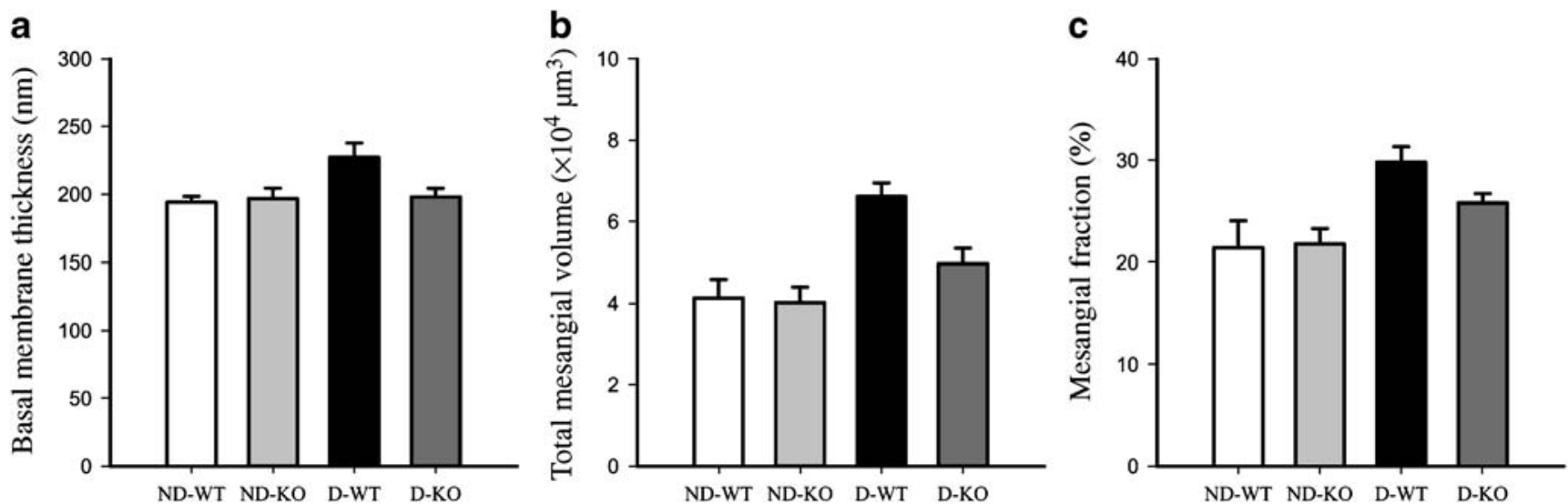

Fig. 2 Glomerular basal membrane thickness (a), total mesangial volume (b) and mesangial fraction (c) in ND-WT $(n=5)$, ND-KO $(n=6)$, D-WT $(n=6)$ and D-KO $(n=5)$ animals. Error bars indicate SEM by group. See "Materials and methods" section and Table 1 for further details 

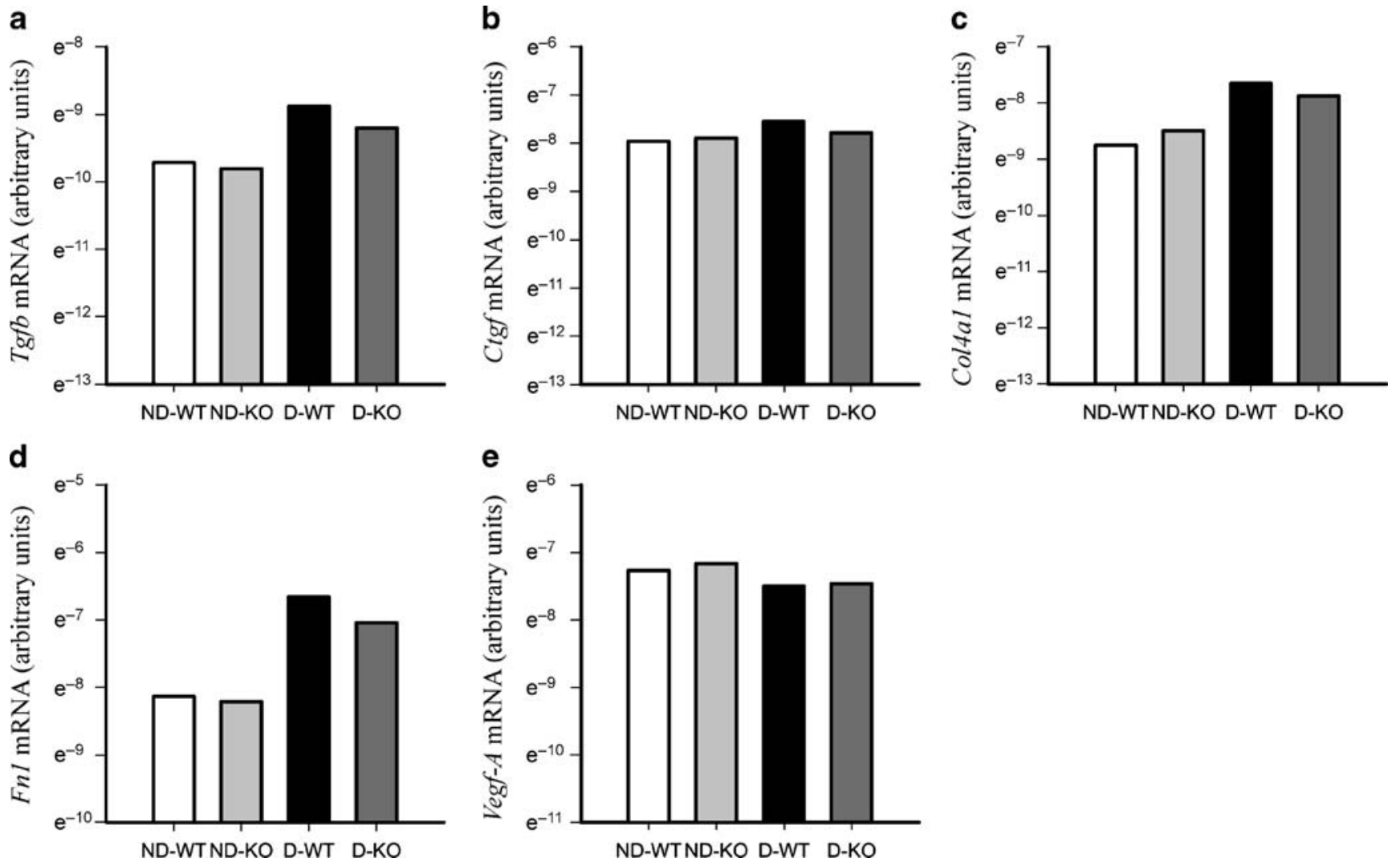

Fig. 3 Renal Tgfb (a), Ctgf (b), Col4al (c), Fnl (d) and Vegf-A (e) mRNA expression in ND-WT $(n=7)$, ND-KO $(n=8)$, D-WT $(n=7[n=$ 6 in collagen data]) and D-KO $(n=6)$ animals. Quantification of mRNA is based on the expression of housekeeping gene $18 S$.

diabetic animals ( $\mathrm{Tg} f b$ increased 2.08 -fold [95\% CI 1.58 2.73, $p<0.001]$ and Ctgf increased by 1.32 -fold [95\% CI $1.08-1.60, p=0.008]$ ). The Col4a 1 expression (Table 1 and Fig. 3) showed interaction between diabetes and MBL ( $p=$ 0.002). Thus, we compared the two non-diabetic groups. The non-diabetic MBL knockout animals had a 1.29-fold (95\% CI 1.07-1.56) higher Col4al expression compared with non-diabetic wild-type animals $(p=0.011)$. Fnl expression showed no interaction between diabetes and MBL $(p=0.232)$ and no effect of MBL $(p=0.092)$. However, diabetes did significantly influence the outcome, as the expression was 3.80 -fold (95\% CI $2.90-4.99)$ increased in the diabetic animals $(p<0.001)$.

Vegf- $A$ expression was not subject to $\mathrm{D} \times \mathrm{MBL}$ interaction $(p=0.542)$. MBL alone had no significant effect on this outcome $(p=0.169)$. The Vegf-A expression in diabetic animals was decreased to $77 \%$ of the non-diabetic level (95\% CI 69.2-85.1, $p<0.001$ ). We found no difference in mean Vegfr-2 or Nphs1 mRNA expressions (data not shown).

Heart and liver weight We found no interaction $(\mathrm{D} \times \mathrm{MBL})$ on heart weight $(p=0.481)$ and no effect of MBL $(p=0.711)$ (Table 1). Looking at diabetes alone we found that diabetic
Statistical analyses were performed on log-transformed data and bars thus indicate geometric means (see Table 1 for back-transformed geometric means and back-transformed 95\% CIs). See Materials and methods section and Table 1 for further details

animals had a significantly decreased heart weight that was $8.4 \mathrm{mg}(95 \%$ CI 3.8-13.0) lower than in non-diabetic animals ( $p=0.001$ ). The liver weights in the four groups were tested by non-parametric tests as data could not be transformed to achieve near-normality. Both diabetic groups showed significantly increased liver weight (median [25\% percentile- $75 \%$ percentile]: $1,155 \mathrm{mg}[1,116-1,203]$ vs $1,396 \mathrm{mg}[1,326-$ $1,454]$ and $1,109 \mathrm{mg}[952.5-1,224]$ vs $1,296 \mathrm{mg}[1,272$ $1,420]$ ) and when compared with the representative nondiabetic control group (i.e. ND-WT vs D-WT, $p<0.001$ and ND-KO vs D-KO, $p=0.004)$. ND-WT animals did not differ significantly from ND-KO animals $(p=0.73)$ and D-WT animals did not differ from D-KO animals $(p=0.09)$.

\section{Discussion}

The major new findings of the present study are that MBL deficiency attenuates several of the classic functional and physical renal changes seen in an experimental model of type 1 diabetes.

The main target of this study was to investigate if MBL had any influence on the alterations normally seen in the kidneys 
in the mouse model of type 1 diabetes we used. By two-way ANOVA analyses we found this to be the case concerning kidney weight, UAE and Col4al mRNA expression. MBL tended to modify the effects of diabetes on BMT and total mesangial volume. Furthermore, we observed marked effects of MBL on both glomerular volume and total mesangial volume as these were smaller in animals lacking MBL. All renal effects of MBL deficiency were observed without effects on blood glucose, BW or food consumption, thus indicating a specific role of MBL in the pathogenesis of diabetes-induced renal changes.

MBL initiates the complement system via the MBL pathway by its binding to repetitive carbohydrate structures found on microorganisms $[3,14]$. This interaction activates the MBL-associated serine proteases, which then cleave $\mathrm{C} 4$ and $\mathrm{C} 2$. This results in generation of $\mathrm{C} 3$ convertase, which initiates the rest of the complement cascade, and generation of the membrane-attack complex (MAC) on the surface of the pathogen. This can cause its lysis. The complement activation also generates fragments that are opsonic, chemotactic and, as recently discovered, bactericidal [15].

The serum level of MBL varies considerable (1,000fold) in the Europid population and the individual level is mainly genetically determined with relatively small fluctuations [16]. The median level of MBL in serum is $800-1,000 \mu \mathrm{g} / 1$, but in one-third of the population the level is $<500 \mu \mathrm{g} / 1$ and in about one-tenth even lower than $100 \mu \mathrm{g} / 1[17,18]$.

In clinical trials, normoalbuminuric patients with type 1 diabetes have higher serum MBL levels than non-diabetic controls $[4,5]$. The groups had the same distribution of MBL genotypes [5]. In these studies, MBL levels correlated with UAE within the normal range, but not with metabolic control. The serum MBL levels were increased in microalbuminuric type 1 diabetic patients when compared with normoalbuminuric patients [6]. Diabetic nephropathy was more prevalent among type 1 diabetic patients with a high MBL expression genotype and high circulating MBL levels than among patients with a low MBL genotype and low serum MBL levels [5]. In a recent study in type 1 diabetic patients, followed for 18 years from diagnosis, high MBL level at baseline was a significant predictor of the development of either microalbuminuria or overt nephropathy [7].

In support of these indirect clinical data indicating an importance of MBL levels in diabetic nephropathy, the present study provides direct evidence for an involvement of MBL in the pathogenesis of diabetic kidney disease. Interaction of MBL and diabetes regarding kidney weight, Col4A1 mRNA expression and albumin excretion demonstrate attenuated renal effects of diabetes in a completely MBL-deficient state.

The crucial role of various growth factors and cytokines in the pathogenesis of diabetic kidney disease has recently been reviewed [19]. $T g f b$ has been shown to be involved in the pathogenesis of diabetic kidney disease in different animal models [20-22]. Furthermore, it has been suggested that CTGF plays a role in diabetic kidney disease partly modulated by TGF- $\beta$ signalling [23-25]. TGF- $\beta$ and CTGF are thought to induce renal fibrosis in part through an upregulation of Col4al and Fn1 expression [23, 24]. In the present study we observed interaction between diabetes and MBL on Col4al expression. This means that the effect of diabetes on Col4al expression is strongly modified by MBL. $T g f b, C t g f$ and $F n l$ did not show any interaction or isolated effect of MBL status. The expression of these three genes was only affected by diabetes, causing an increase in expression.

VEGF-A is produced in the podocytes and has been shown to be upregulated in different animal models of diabetes, e.g. in the STZ-diabetic rat [26-30]. In these studies the most pronounced upregulation was observed in the early stages of the disease. In vitro experiments have demonstrated an increased proliferation and collagen production in mesangial cells in response to VEGF exposure $[31,32]$. Vegfr-2 has been shown to be upregulated in the early stage of diabetes, but not in long-term diabetes [27]. Deterioration of the slit diaphragm is associated with decreased glomerular filter integrity [33]. The existence and function of this diaphragm is critically dependent on nephrin and decreased production of this protein has been observed in different types of kidney disease [34, 35]. Decreased Fnl expression has been observed in long-term diabetes, but not in the early stage of the disease [36].

In the present study we observed no diabetes $\times \mathrm{MBL}$ interaction on $V e g f-A$ expression or any separate effect of MBL. Diabetic animals had significantly lower Vegf-A expression than the non-diabetic animals. This is consistent with another study from our group on STZ-diabetic mice killed after 60 days with diabetes [37]. Expression of Vegfr-2 and Nphs1 did not differ between the four groups in the present study. The time-point for the determination of mRNA expression might explain the disagreement of our observations with prior reports concerning VEGF-A. The equal expression of Vegfr-2 in the four groups in the present study is in agreement with previous results that demonstrated an enhanced expression of the receptor only in the early course of diabetes [27]. Likewise the lack of difference in Nphs 1 expression may be explained by the determination of mRNA levels earlier than in previously reports [36].

In patients with diabetes the complement system could potentially be activated through different mechanisms. An inactivation of the complement regulatory proteins by glycation has been postulated. Under normal conditions complement regulatory proteins, e.g. CD59, prevent formation of MACs on the self-tissue. The increased blood glucose in diabetic patients could induce glycation of complement regulatory proteins and by this mean inactivate the proteins 
[38]. Glycation of CD59 happens in vivo in humans, but not in C57 mice. This glycation attenuates its capacity to inhibit MAC formation [38]. It has been shown that MAC formation happens on cells and can lead to the release of growth factors without effects on cell viability [39]. Immunohistochemical studies observed no normal CD59 in the areas with severe glomerulosclerotic tissue and pronounced MAC deposition in diabetic patients [40]. In another study, deposition of glycated CD59 was observed in the kidneys and nerves of diabetic patients, but not in nondiabetic patients. In about $60 \%$ of the same samples MACs were found colocalised with glycated CD59 [41]. Erythrocytes from diabetic patients were more susceptible to MACmediated lysis compared with those from non-diabetic subjects due to inactivation of CD59 by glycation [41].

In conclusion, intensive metabolic and antihypertensive management remain cornerstones in the treatment of diabetic patients with micro- or macrovascular complications. An emerging amount of evidence suggests that the complement system may offer a strategy of intervention against the progression or even development of vascular complications to diabetes. Multiple drugs for specific manipulation of the complement system, e.g. a soluble complement receptor 1 , and a specific $\mathrm{C} 5$ inhibitor, are under clinical evaluation [42-44]. Whether or not these drugs will provide new treatments of diabetic complications is still unknown. MBL deficiency is known to be associated with an increased risk of a broad range of infections [4547] and adverse effects of inhibition of the complement system might hinder manipulation on a long-term basis.

Acknowledgements The excellent technical assistance of $\mathrm{K}$. Mathiassen, K. Nyborg, B. Grann and I. B. Kristoffersen is appreciated. We are very thankful for the donation of MBL double knockout mice by K. Takahashi, Boston, MA, USA. Thanks are due to M. Erlandsen, Institute of Biostatistics, University of Aarhus for statistical advice. The work was supported by the Danish Medical Research Council, the Eva and Henry Frænkels Memorial Foundation, the Danish Diabetes Association and the Clinical Institute, University of Aarhus, Denmark. An abstract of the study was presented as a poster (no. 1020) at the annual meeting of the European Association for the Study of Diabetes in Athens, Greece, 10-15 September 2005 and as a poster (no. THPO354) at the annual meeting of the American Society of Nephrology, Philadelphia, PA, USA, 10-13 November 2005.

Duality of interest No conflict of interest exists for any of the authors.

\section{References}

1. Hovind P, Tarnow L, Rossing K et al (2003) Decreasing incidence of severe diabetic microangiopathy in type 1 diabetes. Diabetes Care 26:1258-1264

2. Yokoyama H, Okudaira M, Otani T et al (2000) Higher incidence of diabetic nephropathy in type 2 than in type 1 diabetes in earlyonset diabetes in Japan. Kidney Int 58:302-311
3. Østergaard J, Hansen TK, Thiel S, Flyvbjerg A (2005) Complement activation and diabetic vascular complications. Clin Chim Acta 361:10-19

4. Hansen TK, Thiel S, Knudsen ST et al (2003) Elevated levels of mannan-binding lectin in patients with type 1 diabetes. J Clin Endocrinol Metab 88:4857-4861

5. Hansen TK, Tarnow L, Thiel S et al (2004) Association between mannose-binding lectin and vascular complications in type 1 diabetes. Diabetes 53:1570-1576

6. Saraheimo M, Forsblom C, Hansen TK et al (2004) Increased levels of mannan-binding lectin in type 1 diabetic patients with incipient and overt nephropathy. Diabetologia 48:198-202

7. Hovind P, Hansen TK, Tarnow L et al (2005) Mannose-binding lectin as a predictor of microalbuminuria in type 1 diabetes: an inception cohort study. Diabetes 54:1523-1527

8. Shi L, Takahashi K, Dundee J et al (2004) Mannose-binding lectin-deficient mice are susceptible to infection with Staphylococcus aureus. J Exp Med 199:1379-1390

9. Jaffé M (1886) Uber den Niederschlag welchen Pikrinsäure in normalem Harn erzeugt und ueber eine neue Reaction des Kreatinins. Z Physiol Chem 10:391-400

10. Myers GL, Miller WG, Coresh J et al (2006) Recommendations for improving serum creatinine measurement: a report from the Laboratory Working Group of the National Kidney Disease Education Program. Clin Chem 52:5-18

11. Pagtalunan ME, Rasch R, Rennke HG, Meyer TW (1995) Morphometric analysis of effects of angiotensin II on glomerular structure in rats. Am J Physiol 268:F82-F88

12. Jensen EB, Gundersen HJ, Osterby R (1979) Determination of membrane thickness distribution from orthogonal intercepts. J Microsc 115:19-33

13. Lihn AS, Bruun JM, He G, Pedersen SB, Jensen PF, Richelsen B (2004) Lower expression of adiponectin mRNA in visceral adipose tissue in lean and obese subjects. Mol Cell Endocrinol 219:9-15

14. Turner MW (2003) The role of mannose-binding lectin in health and disease. Mol Immunol 40:423-429

15. Nordahl EA, Rydengard V, Nyberg P et al (2004) Activation of the complement system generates antibacterial peptides. Proc Natl Acad Sci U S A 101:16879-16884

16. Thiel S, Frederiksen PD, Jensenius JC (2006) Clinical manifestations of mannan-binding lectin deficiency. Mol Immunol 43:86-96

17. Hansen TK, Thiel S, Wouters PJ, Christiansen JS, Van den Berghe G (2003) Intensive insulin therapy exerts antiinflammatory effects in critically ill patients and counteracts the adverse effect of low mannose-binding lectin levels. J Clin Endocrinol Metab 88: $1082-1088$

18. Steffensen R, Thiel S, Varming K, Jersild C, Jensenius JC (2000) Detection of structural gene mutations and promoter polymorphisms in the mannan-binding lectin (MBL) gene by polymerase chain reaction with sequence-specific primers. J Immunol Methods 241:33-42

19. Schrijvers BF, De Vriese AS, Flyvbjerg A (2004) From hyperglycemia to diabetic kidney disease: the role of metabolic, hemodynamic, intracellular factors and growth factors/cytokines. Endocr Rev 25:971-1010

20. Hong SW, Isono M, Chen S, Iglesias-De La Cruz MC, Han DC, Ziyadeh FN (2001) Increased glomerular and tubular expression of transforming growth factor-beta1, its type II receptor, and activation of the Smad signaling pathway in the $\mathrm{db} / \mathrm{db}$ mouse. Am J Pathol 158:1653-1663

21. Pankewycz OG, Guan JX, Bolton WK, Gomez A, Benedict JF (1994) Renal TGF-beta regulation in spontaneously diabetic NOD mice with correlations in mesangial cells. Kidney Int 46:748-758

22. Sharma K, Jin Y, Guo J, Ziyadeh FN (1996) Neutralization of TGF-beta by anti-TGF-beta antibody attenuates kidney hypertrophy and the enhanced extracellular matrix gene expression in STZ-induced diabetic mice. Diabetes 45:522-530 
23. Riser BL, Denichilo M, Cortes P et al (2000) Regulation of connective tissue growth factor activity in cultured rat mesangial cells and its expression in experimental diabetic glomerulosclerosis. J Am Soc Nephrol 11:25-38

24. Twigg SM, Cao Z, MCLennan SV et al (2002) Renal connective tissue growth factor induction in experimental diabetes is prevented by aminoguanidine. Endocrinology 143:4907-4915

25. van Nieuwenhoven FA, Jensen LJ, Flyvbjerg A, Goldschmeding $\mathrm{R}$ (2005) Imbalance of growth factor signalling in diabetic kidney disease: is connective tissue growth factor (CTGF, CCN2) the perfect intervention point? Nephrol Dial Transplant 20:6-10

26. Cha DR, Kang YS, Han SY et al (2004) Vascular endothelial growth factor is increased during early stage of diabetic nephropathy in type II diabetic rats. J Endocrinol 183:183-194

27. Cooper ME, Vranes D, Youssef $S$ et al (1999) Increased renal expression of vascular endothelial growth factor (VEGF) and its receptor VEGFR-2 in experimental diabetes. Diabetes 48:2229-2239

28. Senthil D, Choudhury GG, McLaurin C, Kasinath BS (2003) Vascular endothelial growth factor induces protein synthesis in renal epithelial cells: a potential role in diabetic nephropathy. Kidney Int 64:468-479

29. Tsuchida K, Makita Z, Yamagishi S et al (1999) Suppression of transforming growth factor beta and vascular endothelial growth factor in diabetic nephropathy in rats by a novel advanced glycation end product inhibitor, OPB-9195. Diabetologia 42:579-588

30. Yamamoto Y, Maeshima Y, Kitayama H et al (2004) Tumstatin peptide, an inhibitor of angiogenesis, prevents glomerular hypertrophy in the early stage of diabetic nephropathy. Diabetes 53:1831-1840

31. Amemiya T, Sasamura H, Mifune M et al (1999) Vascular endothelial growth factor activates MAP kinase and enhances collagen synthesis in human mesangial cells. Kidney Int 56:2055-2063

32. Thomas S, Vanuystel J, Gruden G et al (2000) Vascular endothelial growth factor receptors in human mesangium in vitro and in glomerular disease. J Am Soc Nephrol 11:1236-1243

33. Hamano Y, Grunkemeyer JA, Sudhakar A et al (2002) Determinants of vascular permeability in the kidney glomerulus. J Biol Chem 277:31154-31162

34. Kawachi H, Koike H, Shimizu F (2002) mAb 5-1-6 nephropathy and nephrin. Microsc Res Tech 57:236-240

35. Wartiovaara J, Ofverstedt LG, Khoshnoodi J et al (2004) Nephrin strands contribute to a porous slit diaphragm scaffold as revealed by electron tomography. J Clin Invest 114:1475-1483

36. Kelly DJ, Aaltonen P, Cox AJ et al (2002) Expression of the slitdiaphragm protein, nephrin, in experimental diabetic nephropathy: differing effects of anti-proteinuric therapies. Nephrol Dial Transplant 17:1327-1332

37. Jensen LJ, Denner L, Schrijvers BF, Tilton RG, Rasch R, Flyvbjerg A (2006) Renal effects of a neutralising RAGEantibody in long-term streptozotocin-diabetic mice. J Endocrinol 188:493-501

38. Acosta J, Hettinga J, Fluckiger R et al (2000) Molecular basis for a link between complement and the vascular complications of diabetes. Proc Natl Acad Sci U S A 97:5450-5455

39. Benzaquen LR, Nicholson-Weller A, Halperin JA (1994) Terminal complement proteins C5b-9 release basic fibroblast growth factor and platelet-derived growth factor from endothelial cells. J Exp Med 179:985-992

40. Uesugi N, Sakata N, Nangaku M et al (2004) Possible mechanism for medial smooth muscle cell injury in diabetic nephropathy: glycoxidation-mediated local complement activation. Am J Kidney Dis 44:224-238

41. Qin X, Goldfine A, Krumrei N et al (2004) Glycation inactivation of the complement regulatory protein CD59: a possible role in the pathogenesis of the vascular complications of human diabetes. Diabetes 53:2653-2661

42. Granger CB, Mahaffey KW, Weaver WD et al (2003) Pexelizumab, an anti-C5 complement antibody, as adjunctive therapy to primary percutaneous coronary intervention in acute myocardial infarction: the Complement Inhibition in Myocardial Infarction Treated with Angioplasty (COMMA) Trial. Circulation 108:1184-1190

43. Verrier ED, Shernan SK, Taylor KM et al (2004) Terminal complement blockade with pexelizumab during coronary artery bypass graft surgery requiring cardiopulmonary bypass: a randomized trial. JAMA 291:2319-2327

44. Zimmerman JL, Dellinger RP, Straube RC, Levin JL (2000) Phase I trial of the recombinant soluble complement receptor 1 in acute lung injury and acute respiratory distress syndrome. Crit Care Med 28:3149-3154

45. Garred P, Madsen HO, Hofmann B, Svejgaard A (1995) Increased frequency of homozygosity of abnormal mannan-binding-protein alleles in patients with suspected immunodeficiency. Lancet 346:941-943

46. Garred P, Madsen HO, Balslev U et al (1997) Susceptibility to HIV infection and progression of AIDS in relation to variant alleles of mannose-binding lectin. Lancet 349:236-240

47. Summerfield JA, Sumiya M, Levin M, Turner MW (1997) Association of mutations in mannose binding protein gene with childhood infection in consecutive hospital series. BMJ 314:1229-1232 